\title{
Analysis of Single Vendor - Multi Buyer Consignment Inventory
}

\author{
Chidurala Srinivas ${ }^{1}$, A. Raji Reddy ${ }^{2}$ \\ ${ }^{\text {I}}$ (Professor, Mechanical Engineering Dept., Vaageswari College of Engineering, Karimnagar, India \\ ${ }_{2}^{2}$ (Professor, Mechanical Engineering Dept., CMR Technical Campus, Hyderabad, India
}

\begin{abstract}
Some significant strategies or practices for streamlining inventory along the supply chain include Consignment models. This paper describes the benefits of Consignment Policy inventory models of single vendor - multi buyer model which is view as a classification of divergent supply chain with end to multi end case which is a distinctive flavor of Vendor Managed Inventory. The change of ownership commences during pull system at which the payment is made to vendor. It evaluates minimum joint total expected cost of vendor and buyer, simultaneously optimise quantitative decision variables. Numerical examples are presented to illustrate the benefit of the proposed strategies and the effects of changes on the cost and parameters are studied.
\end{abstract}

Keywords: Consignment Policy, Delay delivery, Information sharing.

\section{Introduction}

The field of production and inventory planning and control has moved from elementary rules of thumb used within four walls of factory to sophisticated computer algorithms shared among the trading partners in supply network. With reference to Figure.1, it can predict Vendor Managed Inventory (VMI) is transforming into Consignment Inventory (CI) approach and then elimination of intermediary channels is possible and hence direct selling which gives more profits. Different models have formulated to minimize joint total expected cost of single vendor - multi buyer (upto two buyers) and simultaneously optimize other decision variables such as quantity transported, number of transport operations, delay deliveries and buyer maximum and minimum stocks under stochastic environment.

The basic fundamental of consignment policy is explained in Braglia and Zavanella [1], Valentini and Zavanella [2], Simone and Grubbstrom [3]. Goyal [4] proposed a joint economic lot size model to minimize total costs and is compared with total costs incurred if vendor and buyer act independently. Banerjee [5] generalized Goyal's [4] model by assuming vendor with finite rate produces for a buyer on a lot-for-lot basis under deterministic conditions. Goyal [6] generalized the Banerjee [2] model by relaxing the assumption of the lot-for-lot policy of the vendor.

In CI model vendor use buyer warehouse for keeping the goods produced by the vendor without changing the ownership. To fulfill this concept, the vendor should be close to the buyer production line. This creates a condition of shared benefit, neither the vendor nor the buyer will benefit until the product is sold to an end user. This shared risk benefit condition will often be enough to convince the buyer to stock the products. The key benefit to the buyer should be obvious, that the buyer doesn't have to tie up capital hb, finance. This doesn't mean that there is no inventory carrying costs for the buyer they do still incur costs hb, stock related to storing and managing the inventory i.e., both parties incur holding cost, depending on different rates and the length of time for which materials has been stocked in supply chain (SC). Finally, the buyer sees a lower inventory cost per unit i.e., only hb, stock instead of the entire $h b$, stock $+h b$, finance. The vendor will have setup cost and holding cost whereas the buyer will have order emission cost and holding cost. Typically, it is suitable for automobile components, fashion products, pharmaceutical, electronic, fast moving consumer goods, retail items of super and hypermarkets. In some sectors, consignment inventory would be around $15-20 \%$ of total inventory.

\begin{tabular}{|c|c|c|c|c|}
\hline $\begin{array}{c}\text { Owner } \\
\text { Managed } \\
\text { Inventory }\end{array}$ & $\begin{array}{c}\text { Continuous } \\
\text { Replenishment }\end{array}$ & $\begin{array}{c}\text { Vendor } \\
\text { Managed } \\
\text { Inventory }\end{array}$ & $\begin{array}{c}\text { Consignment } \\
\text { Inventory }\end{array}$ & $\begin{array}{c}\text { Direct } \\
\text { selling }\end{array}$
\end{tabular}

Figure 1: Conceptual evaluation of consignment policy 


\section{Formulation of Models}

In single vendor - multi buyer two models such as consignment policy with delay deliveries and consignment policy with delay deliveries with information sharing have developed and evaluated. All these models are referring to stochastic customer demand.

\section{Notations are given below:}

Di Demand per unit time on the buyer

$\mathrm{P} \quad$ Production rate on the vendor

c ordering and production cycle time

$\mathrm{Ai} \quad$ Buyer i ordering cost per order

Ati Transportation cost per shipment

ni number of lots

S Vendor's set-up cost per set-up

hv Vendor's holding cost rate per unit time

hbi Buyer i holding cost rate per unit time

$\pi \quad$ Unit backorder cost for the buyer

qi Order quantity of the buyer i per shipment (decision variable).

$\mathrm{Ri} \quad$ Reorder point of the buyer i (decision variable).

$\mathrm{Li} \quad$ Length of lead time for the buyer i.

$\sigma \quad$ Standard deviation of demand of buyer i per unit time

k1 Delay deliveries

m Delayed deliveries shifted to different buyers $(\leq \mathrm{k} 1)$

\section{Consignment Inventory with Delay Deliveries}

The Consignment Inventory (CI) model is not suitable for small periods because maximum level of buyer's inventory may reach even for limited periods. Hence CI model with delayed delivery period (CI-k1) is preferred for limited periods. In CI-k1 model, the last delivery is delayed until it reaches that there is no longer an increase in the maximum level already reached. That means, we have to delay the delivery always whenever maximum level inventory stock is reached.

Joint total cost of single vendor two buyers is,

$$
T_{c}^{C I-k^{1}}=\frac{G(n)}{c}+H(n) c+\frac{\pi_{1} \sigma_{1} \sqrt{L_{1}} \Psi(z)+\pi_{2} \sigma_{2} \sqrt{L_{2}} \Psi(z)}{c}+h_{b 1} z \sigma_{1} \sqrt{L_{1}}+h_{b 2} z \sigma_{2} \sqrt{L_{2}}
$$

Where,

$$
G(n)=s+A_{1}+A_{2}+n_{1} \cdot A_{t 1}+n_{2} \cdot A_{t 2}
$$

and

$$
\begin{aligned}
& H(n)=h_{v}\left\{\frac{1}{2 p}\left[\frac{D_{1}^{2}}{n_{1}}+\frac{D_{2}^{2}}{n_{2}}\right]+\frac{D_{1}}{n_{1}} \cdot \frac{\left(p-D_{1}\right)}{n_{1} p} \cdot \frac{\left(k_{1}+1\right)}{2} \cdot k_{1}+\frac{D_{2}}{n_{2}} \cdot \frac{\left(p-D_{2}\right)}{n_{2} p} \cdot \frac{\left(k_{2}+1\right)}{2} \cdot k_{2}\right\} \\
& +\frac{h_{b 1}}{2}\left\{\left(n_{1}-k_{1}\right) \frac{D_{1}}{n_{1}}-\left(n_{1}-k_{1}-1\right) \cdot D_{1} \cdot\left[\frac{D_{1}}{n_{1} p}+\frac{D_{2}}{n_{2} p}\left(\frac{n_{2}}{n_{1}}\right)\right]\right\} \\
& +\frac{h_{b 2}}{2}\left\{\left(n_{2}-k_{2}\right) \frac{D_{2}}{n_{2}}-\left(n_{2}-k_{2}-1\right) \cdot D_{2} \cdot\left[\frac{D_{2}}{n_{2} p}+\frac{D_{1}}{n_{1} p}\left(\frac{n_{1}}{n_{2}}\right)\right]\right\}
\end{aligned}
$$

\section{CI With Delay Deliveries and with Information Sharing}

In consignment policy with information sharing model include information of demand, and inventory. It is known that information sharing benefit the vendor more compare with buyer due to reduction in vendor inventory and also due to adjusted shipments between buyers, other wise the vendor may have to keep. In this view, supply chain is constructed in such a way that if buyer doesn't need a particular scheduled delivery lot, the vendor finds an alternate buyer in the SC network. To fulfill this, the vendor adjusts exact delivery quantity required to the alternate buyer, i.e., the shifted quantity should be equal to scheduled quantity of alternate buyer.

Joint total cost of single vendor two buyers is,

$$
\begin{aligned}
& T_{c}^{C I-k^{1}-I S}=\frac{G(n)}{c}+H(n) c+\frac{\pi_{1} \sigma_{1} \sqrt{L_{1}} \Psi(z)+\pi_{2} \sigma_{2} \sqrt{L_{2}} \Psi(z)}{c} \\
& +h_{b 1} z \sigma_{1} \sqrt{L_{1}}+h_{b 2} z \sigma_{2} \sqrt{L_{2}}
\end{aligned}
$$


where,

$$
\begin{aligned}
& G(n)=s+A_{1}+A_{2}+n_{1} \cdot A_{t 1}+n_{2} \cdot A_{t 2} \\
& H(n)=h_{v}\left\{\frac{1}{2 p}\left[\frac{D_{1}^{2}}{n_{1}}+\frac{D_{2}^{2}}{n_{2}}\right]+\frac{D_{1}}{n_{1}} \frac{\left(p-D_{1}\right)}{n_{1} p} \frac{\left(k_{1}-m_{1}+1\right)}{2}\left(k_{1}-m_{1}\right)+\frac{D_{2}}{n_{2}} \frac{\left(p-D_{2}\right)}{n_{2} p} \frac{\left(k_{2}-m_{2}+1\right)}{2}\left(k_{2}-m_{2}\right)\right\} \\
& +\frac{h_{b 1}}{2}\left\{\left(n_{1}-k_{1}+j_{21}\right) \frac{D_{1}}{n_{1}}-\left(n_{1}-k_{1}-1+j_{21}\right) D_{1}\left[\frac{D_{1}}{n_{1} p}+\frac{D_{2}}{n_{2} p}\left(\frac{n_{2}}{n_{1}}\right)\right]\right\} \\
& +\frac{h_{b 2}}{2}\left\{\left(n_{2}-k_{2}+j_{12}\right) \frac{D_{2}}{n_{2}}-\left(n_{2}-k_{2}-1+j_{12}\right) D_{2}\left[\frac{D_{2}}{n_{2} p}+\frac{D_{1}}{n_{1} p}\left(\frac{n_{1}}{n_{2}}\right)\right]\right\}
\end{aligned}
$$

\section{Results and Discussion}

The input values to all the models discussed are refer to Ben-Daya and Raouf [7], Braglia and Zavanella [1]: hv $=\$ 4$ per unit/year, hbi $=\$ 5$ per unit/year, $\mathrm{d} 1,2=1000,1300, \mathrm{p} / \sum \mathrm{di}=3.2, \sigma 1,2=44.72,50$, $\mathrm{Av}=\$ 400 /$ set up, Ab1,2 =\$25/order, $\pi=\$ 50 /$ unit. Lead time is 14 days. The proposed models of single vendor - multi buyer gives cost average savings in JTEC with information sharing is $4.5 \%$ with maximum of $9 \%$ when

\begin{tabular}{|c|c|c|c|c|c|}
\hline Strategy & $\begin{array}{l}\text { cycle time } \\
\text { (years) }\end{array}$ & \begin{tabular}{|ll} 
number & of \\
shipments and \\
delay deliveries
\end{tabular} & $\begin{array}{l}\text { shipment } \\
\text { size }\end{array}$ & $\begin{array}{l}\text { Maximum } \\
\text { level of buyer } \\
\text { stock }\end{array}$ & $\begin{array}{l}\text { Reorder } \\
\text { point }\end{array}$ \\
\hline $\begin{array}{l}\text { CI with delay } \\
\text { delivery }\end{array}$ & 0.53 & $\begin{array}{l}\mathrm{n} 1=5, \mathrm{n} 2=5 \\
\mathrm{k} 1=2, \mathrm{k} 2=2\end{array}$ & $\begin{array}{l}\mathrm{q} 1=105 \\
\mathrm{q} 2=136\end{array}$ & $\begin{array}{l}\mathrm{b} 1 \mathrm{max}=520 \\
\mathrm{~b} 2 \mathrm{max}=626\end{array}$ & $\begin{array}{l}\text { ROP1 }=310 \\
\text { ROP2 }=353\end{array}$ \\
\hline $\begin{array}{l}\text { CI with delay } \\
\text { with Information } \\
\text { sharing }\end{array}$ & 0.614 & $\begin{array}{l}\mathrm{n} 1=8, \mathrm{n} 2=4 \\
\mathrm{k} 1=3, \mathrm{k} 2=3 \\
\mathrm{j} 21=3\end{array}$ & $\begin{array}{l}\mathrm{q} 1=77 \\
\mathrm{q} 2=200\end{array}$ & $\begin{array}{l}\mathrm{b} 1 \max =705 \\
\mathrm{~b} 2 \max =488\end{array}$ & $\begin{array}{l}\text { ROP1 }=296 \\
\text { ROP2 }=338\end{array}$ \\
\hline
\end{tabular}
it compared to CI models for input of Braglia and Zavanella [1] and with decrease tendency. It is observed that the percentage of savings obtained by CI-k1 and CI-k1-IS decrease with buyer size increase.

Table 1: Optimum values for single vendor two buyer model

Table 2: Comparison of values for single vendor two buyer model

\begin{tabular}{|l|l|l|l|}
\hline Strategy & Total vendor cost & Total buyer cost & JTEC \\
\hline CI with delay delivery & 1327 & $\begin{array}{l}\text { Tb1=2570 } \\
\text { Tb2=2958 }\end{array}$ & 6855 \\
\hline $\begin{array}{l}\text { CI with delay with } \\
\text { Information sharing }\end{array}$ & 941 & $\begin{array}{l}\text { Tb1=3094 } \\
\text { Tb2=2510 }\end{array}$ & 6545 \\
\hline
\end{tabular}

Table 1 shows results obtained by complete enumeration for all models. Optimum number of shipments and optimum shipment quantity is also listed. Results of different models are compared. Optimum cycle time for various models is also given. It can be shown that optimum cycle time increases for CI with delay and CI with delay with IS models. Maximum level of inventory reached for buyers also decreases for CI with delay model i.e. because of shifting of inventory from buyers to vendor. Table 2 shows various costs for all models. Total vendor cost consists of set up cost and holding cost for vendor. Total buyer cost consists of ordering cost and holding cost for buyer. JTEC is the summation of vendor's and buyers cost. JTEC of different models is compared percentage savings is calculated. It can be shown that percentage savings is more for CI with delay with information sharing than CI with delay model.

\section{Future Scope of Work}

The future work may be extended to fast moving consumable goods with price discount using controllable lead time.

\section{References}

[1] M.Braglia, LE.Zavanella, Modeling an industrial for inventory management in supply chains: the consignment stock case, International Journal of Production Research, 41(16), 3793-3808, 2003.

[2] G.Valentini, L.E.Zavanella, The consignment stock of inventories: industrial case and performance analysis, International Journal of Production Economics, 81-82, 215-224, 2003.

[3] Z.Simone, R.W.Grubbstrom, A note on an industrial strategy for stock management in supply chains: modeling and performance evaluation, International Journal of Production Research, 42(20),4421-4426,2004.

[4] S.K.Goyal, A joint economic lot size model for purchaser and vendor: a comment, Decision Science, 19(1), 236241,1988 .

[5] A.Banerjee, A joint economic lot size model for purchaser and vendor, Decision Sciences, 17, 292- 311, 1986. 
[6] S.K.Goyal, Determination of optimum production quantity for a two-stage production system, Operational Research Quarterly, 28, 865-870,1977.

[7] M.Ben-Daya, A.Raouf, Inventory models involving lead time as a decision variable, The Journal of the Operational Research Society, 45, 579-582,1994. 